\title{
Stretch occlusion of stone extraction balloon catheter
}

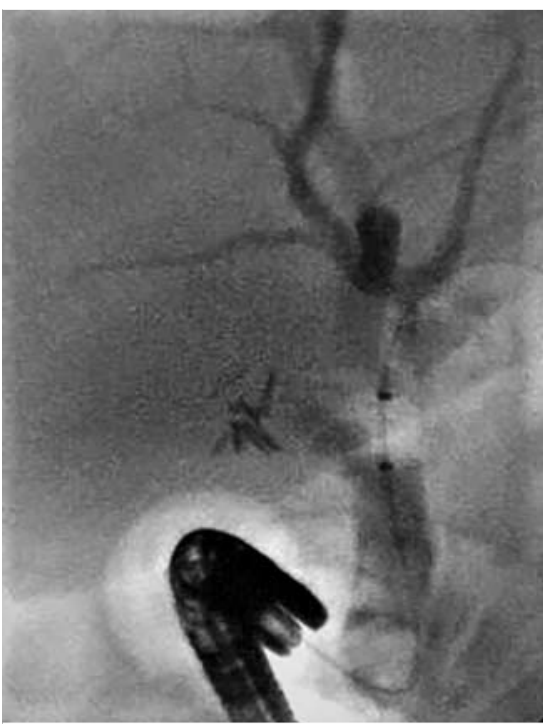

-Fig. 1 Fluoroscopic image: after several attempts of downward pulling on the balloon catheter, aiming for stone expulsion, we were unable to deflate the balloon.

A 65-year-old woman underwent endoscopic retrograde cholangiopancreatography (ERCP) for choledocholithiasis, and a standard stone extraction balloon (Multi-3V; Olympus, Tokyo, Japan) was used initially to remove the stone after biliary sphincterotomy. After several attempts of downward pulling on the balloon catheter, aiming for stone expulsion, we were unable to deflate the balloon ( Fig. 1). No elevator manipulation was used during stone removal. We suspected that the balloon catheter had developed stretch occlusion: total collapse of the air channel within the balloon catheter caused by the stretched surrounding plastic housing catheter. Through this mechanism the air inside the balloon becomes totally trapped above the stretched occlusion site. The balloon could not be deflated even after we cut the catheter close to the handle ( Fig.2). So, the inflated balloon was pulled to the biliary opening. Next to the cut catheter, an endoscopic needle-knife

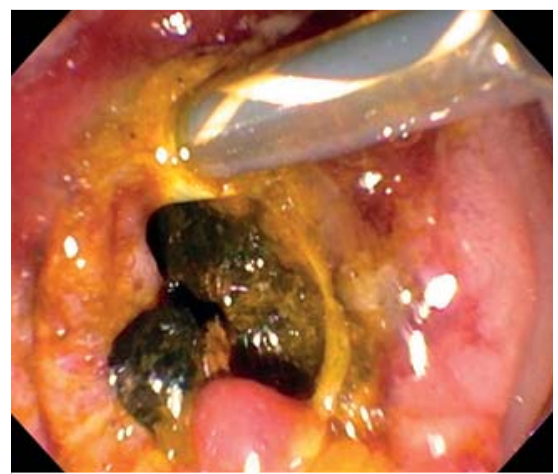

- Fig. 2 Endoscopic image: the balloon could not be deflated even after we cut the catheter close to the handle.

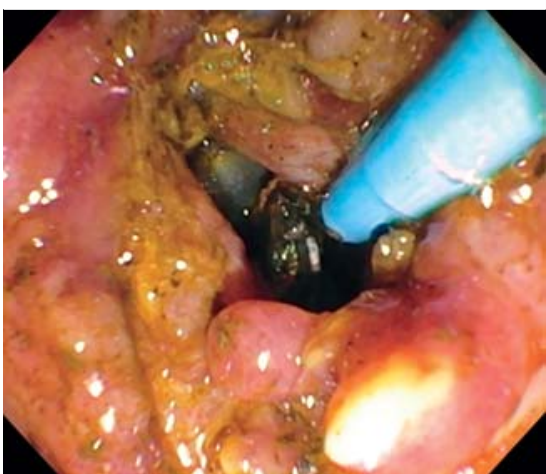

Fig. 3 Endoscopic image: we used an endoscopic needle-knife without cauterization to puncture the inflated balloon.

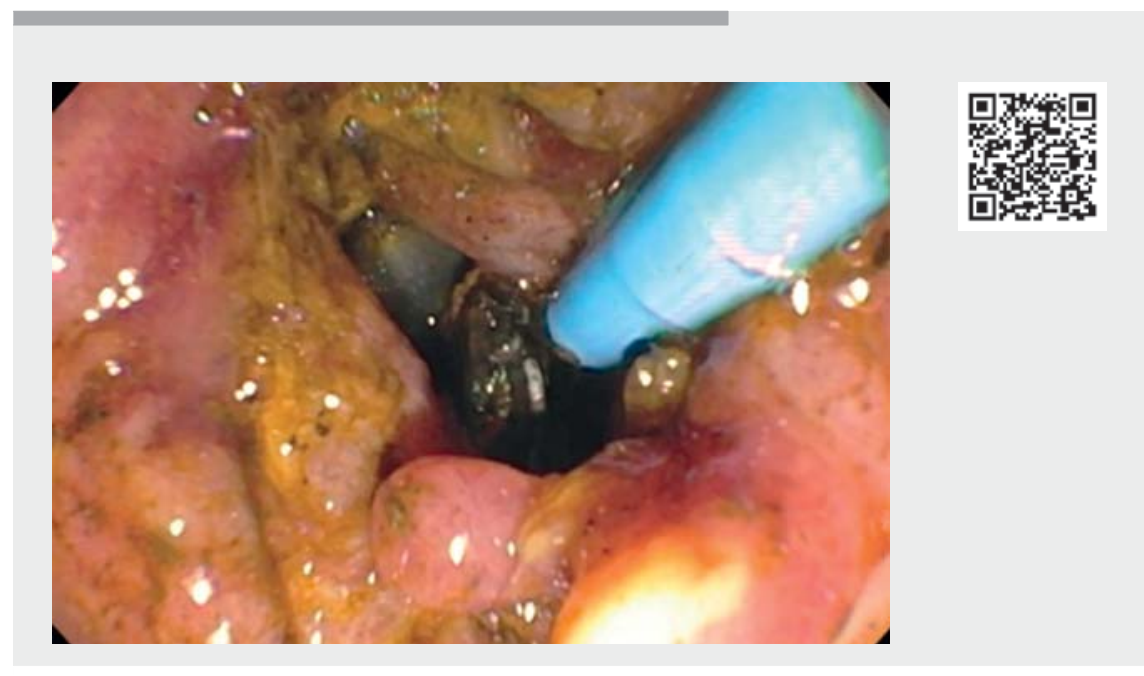

$\checkmark$ Video 1 Stretch occlusion of stone extraction balloon catheter.

without cauterization was used to puncture the inflated balloon ( $>$ Fig. 3 ) under endoscopic and fluoroscopic guidance. The balloon deflated immediately and was removed ( Video $\mathbf{1}$ ). We removed all stone fragments during the same ERCP session. All ERCP endoscopists need to be aware of this rare potential complication when using stone extraction balloons and know how to manage it accordingly.

Endoscopy_UCTN_Code_CPL_1AK_2AF

\section{Competing interests}

The authors declare that they have no conflict of interest.

The author

\section{Shou-jiang Tang}

Division of Digestive Diseases, Department of Medicine, University of Mississippi Medical Center, Jackson, MS 
Corresponding author

Bibliography

Shou-jiang Tang, MD

Division of Digestive Diseases, Department of Internal Medicine, University of Mississippi Medical Center, 2500 North State Street, Jackson, MS 39216, USA

stang@umc.edu
Endoscopy 2022; 54: E199-E200

DOI 10.1055/a-1480-6846

ISSN 0013-726X

published online 12.5.2021

(c) 2021. Thieme. All rights reserved.

Georg Thieme Verlag KG, Rüdigerstraße 14,

70469 Stuttgart, Germany

\section{ENDOSCOPY E-VIDEOS}

https://eref.thieme.de/e-videos

回局 Endoscopy E-Videos is an open access online section, 回躲: reporting on interesting cases and new techniques in gastroenterological endoscopy. All papers include a high quality video and all contributions are freely accessible online. Processing charges apply (currently EUR 375), discounts and wavers acc. to HINARI are available.

This section has its own submission website at

https://mc.manuscriptcentral.com/e-videos 